\title{
Abstracts
}

\section{Gender Issues}

Sheila Peace

\begin{abstract}
Miriam S. Moss, Sidney Z. Moss, Robert Rubinstein and Nancy Resch, Impact of elderly mother's death on middle age daughters. International Journal of Aging and Human Development, 37, I. (1993), I-22.
\end{abstract}

Whilst parental death is becoming a norm for people in middle-age it has been the subject of very little research. Greater concern has been placed on the impact of parental death on younger children; death which appears 'out of time', rather than 'expected and timely'. In addition the literature on bereavement following the death of an older person focuses on the experience of spouses rather than adult children. This paper reports on 'the first extensive longitudinal qualitative study of the many meanings that the death of a widowed mother possibly holds for middle-aged women', and is embedded in the literature on alternative models of bereavement including grief resolution and grief as transition.

In fact the paper features a small sub-set of data from a large survey of 103 women living in Philadelphia and surrounding counties of Pennsylvania and New Jersey. The sample is of married women, living with their husbands, whose father had predeceased their mother, and whose mother had died in the previous $3^{-6}$ months. It divides into four types: heavy care-givers $(\mathrm{N}=19)$-daughters who lived with their mother and cared for them for at least six months prior to the mother's death; nursing home $(\mathrm{N}=27)$ - mother had resided in a nursing home within an hour's drive for at least six months; distant mothers $(N=28)$ - mother had lived at a distance for at least a year prior to death; light care-givers $(\mathrm{N}=28)$ - most mothers were functioning independently in personal care up to the final few months. A range of psychometric scales and questions were used to examine bereavement. The scales are detailed in the paper. The researchers derived a number of variables during their analysis and those reported here include six bereavementoutcome measures called Grief, Somatic, Acceptance, Finitude, Comfort and Reunion. The aim of the paper is to examine a range of themes in response to maternal grief, and to explore its impact in relation to the four different contexts in which death took place. 
The characteristics of mothers and daughters are given across the four groups and show that whilst there are many similarities, there are also some differences. These details will not be given here, rather I shall concentrate on the main findings for the sample as a whole and for the comparison between sub-samples. The Grief measure (which reflects emotional response to death) is found to be central. 'The greater the Grief, the more extensive the Somatic shifts since the death, the less the Acceptance of the death, the greater sense of personal Finitude, and the greater the theme of Reunion'. The bereavement outcomes also have different associations with characteristics of the daughter and terminal functioning of the mother e.g. Grief was greater for younger daughters; Somatic responses were more frequent for daughters who had less sense of personal mastery in their lives; Acceptance was associated with lower levels of mothers' physical and cognitive functioning; greater sense of personal Finitude was positively related to greater sense of guilt and negatively with a greater sense of personal mastery. A range of other interesting associations are given in the paper, and the data forms the basis of regression models which confirm and give greater explanation for these patterns.

In a comparison of the four groups of daughters, no difference was found concerning the measures of Somatic reaction to death, Finitude and Comfort. The major difference in bereavement outcomes was that nursing home daughters had less Grief and greater Acceptance than light caregivers, and were less concerned with Reunion than either light or heavy care-givers. In the discussion of these findings, the authors raise a number of interesting points concerning the impact of parental death on adult children - in this case adult women, and they begin to draw upon their qualitative study. The identification of outcome measures in addition to emotional and somatic responses present fruitful areas for further research. They comment that 'holding on and letting go may represent the central dynamics of parental bereavement'. Factors which assist both 'holding on and letting go' within the mother/ daughter relationship include: age, nature of relationship between mother and daughter, level of frailty of mother in final year, level of the daughter's personal mastery or sense of control and religious beliefs.

The discussion concerning the sub-groups is also revealing. While we might expect that the greater physical and mental frailty of mothers living in nursing homes would account for some of the emotional distance displayed by their daughters, an analysis which controlled for frailty showed that greater acceptance and less grief remained. The authors suggest that, "it appears to be the nursing home tenure itself...that is associated with more acceptance and less grief'. Their qualitative data shows how nursing homes are anticipated as places of 
terminal care and that 'there may be a tendency to let go emotionally of the mother during the nursing home tenure because the move is a formal signal of the end of an active independent life and a precursor to death'. It is the light/non-care-givers who show most intense grief and least acceptance of the death. For many of these daughters death came as something of a shock: this sense of untimeliness is important in their reaction to the death. There is a lack of what the authors call 'terminal dependency' which may prepare daughters for the death.

The authors end by outlining a range options for further research in subject (extending the study to men) and methodology. This is an important study and the data reported here need to be set within the context of the wider qualitative study.

Barbara M. Barer, Men and women aging differently. International Journal of Aging and Human Development, 38, I (1994), 29-40.

One area of research which continues to fascinate gerontologists is the different responses to ageing of men and women. While many 'qualityof-life' studies show that older women have to cope with greater disadvantage than older men in terms of economic resources, chronic long-term disabilities (particularly those which inhibit mobility), the likelihood of living alone, and the experience of widowhood; they also reveal differences in how men and women cope. This paper adds to our knowledge by considering the lives of people aged over 85 years. It reports the findings from a study of 150 white-Americans living in San Francisco $(\mathrm{N}=1$ I I women, mean age 89.2 years; $\mathrm{N}=39$ men, mean age 88. I years).

The characteristics of the sample hold few surprises and confirm much that is already known. The men were fitter, more active and economically advantaged : $49 \%$ were married (compared to 10\% of women) and only $46 \%$ lived alone (compared to $62 \%$ of women). Women, however, received more support from children and maintained more contact with them. They were also more likely than the men to name a friend as a confidante. The study highlights gender as an important variable in the development and maintenance of social resources, and it considers these resources in relation to how individuals manage their daily routines. Thus while the women did 'more socializing on a daily basis', the men 'maintained a higher level of activity', being more involved in hobbies and household maintenance. Not surprisingly, the men maintained greater control over the physical environment, but gender differences were not seen in relation to social integration or to a sense of well-being (we are not told how these 
variables were measured). The author uses case study material to illustrate some of the differences in patterns of activity.

The most interesting part of this paper was found to be the discussion of 'life course trajectories' and the importance of looking at how men and women within particular age-cohorts experience events at different times. The author suggests that the timing of events for men and women may lead to different types of adaptation or forms of coping. She considers three areas: widowhood, care-giving and relocation. Given that this is a sample of those aged 85 years and over, there are many more widows than widowers and they have been widowed for longer (a mean of 25 years for widows and io years for widowers). She argues that women 'have had time to build networks that substitute for the sociability of marriage' and 'have had more years than men to adapt emotionally to their losses'. These arguments are supported with qualitative data which show, in particular, the isolation of many of the widowers in their eighties who rarely invest their energies in new relationships. On the other hand, the women are shown as more actively engaged within networks maintained and developed over a lifetime, and drawn upon during several decades of widowhood.

Care-giving is a role which many women take on throughout their lives. In this study, some of the male respondents were coming to care-giving in their eighties and finding this role extremely stressful, something they never expected to take on. The change in lifestyle initiated by relocation is also of interest. Here the women were more likely to have relocated to senior housing at a much earlier time of life, often as a consequence of widowhood, reduced financial circumstances or the need for a more supportive environment due to their own illhealth. They appear much more positive about their change in environment than the male respondents who have moved at a much later stage in their lives. The author states that ' widowhood, caregiving and relocation are off-time events and rarely anticipated in the lives of very old men, so they usually have difficulty in coping with them'. The importance of gender and age, itself, in our understanding of coping with stressful life events at the end of life are partially explored in this paper. But we are left with questions such as: what of the impact of class, race and culture? what of the importance of individual personality? what of the importance of role socialisation within a particular generational and cultural context?

Department of Health and Social Welfare,

The Open University,

Milton Keynes, Buckinghamshire 